\title{
Endoscopic removal of a fractured partially covered Evolution esophageal stent
}

Self-expanding metal esophageal stents have been increasingly utilized in the treatment of benign strictures that are refractory to dilation [ $1-3]$. The radial force of the stent and resulting tissue hyperplasia often make subsequent stent retrieval difficult. Complications range from a need for multiple repeat procedures to perforation requiring surgical intervention $[4,5]$.

A 67-year-old man with a history of esophageal carcinoma treated with esophagectomy and gastric pull-up developed dysphagia related to a benign anastomotic stricture. Endoscopic balloon dilation did not alleviate his symptoms and an Evolution stent (EVO-20-25-10-E, Cook Medical, Winston-Salem, North Carolina, USA) was deployed across the stricture. However, 2 months following stent placement, the patient developed dyspnea, and a computed tomography (CT) scan demonstrated edematous tissue surrounding the stent and causing a mass effect on the trachea ( $\bullet$ Fig. 1). Two Polyflex (M00514300, Boston Scientific, Natick, Massachusetts, USA) stents were deployed to facilitate mucosal pressure necrosis and removal of the Evolution stent, but this was unsuccessful. The upper portion of the Evolution stent fractured during a removal attempt and the patient developed stridor requiring intubation.

The patient was transferred to us. We performed flexible endoscopy using a 6-mm channel endoscope (Olympus XTQ160, Olympus America Inc., Center Valley, Pennsylvania, USA) equipped with three rat tooth forceps to pull the uncovered portion of the stent into the channel, causing partial collapse of the proximal stent. We then used argon plasma coagulation to cut the remaining embedded upper flanges, following which our otolaryngology colleagues introduced a Weerda distending diverticuloscope (Karl Storz, Tuttlingen, Germany; 12067b, length $24 \mathrm{~cm}$ ). Heavy alligator forceps were deployed through a rigid 4-mm endoscope to elevate the stent circumferentially until it was freed from the mucosa ( Fig. 2, Video 1). At the 3-month follow-up, the gastroesophageal anastomo-

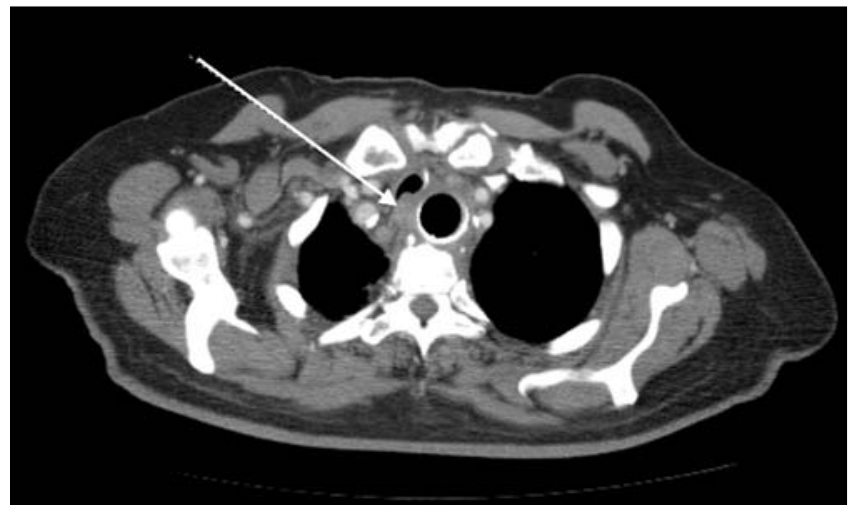

Fig. 1 Computed tomography (CT) scan taken 2 months after esophageal stent placement in a 67-year-old man with dysphagia related to a benign anastomotic stricture. The scan shows edema abutting the right proximal portion of the stent with mass effect on the adjacent trachea (arrow).

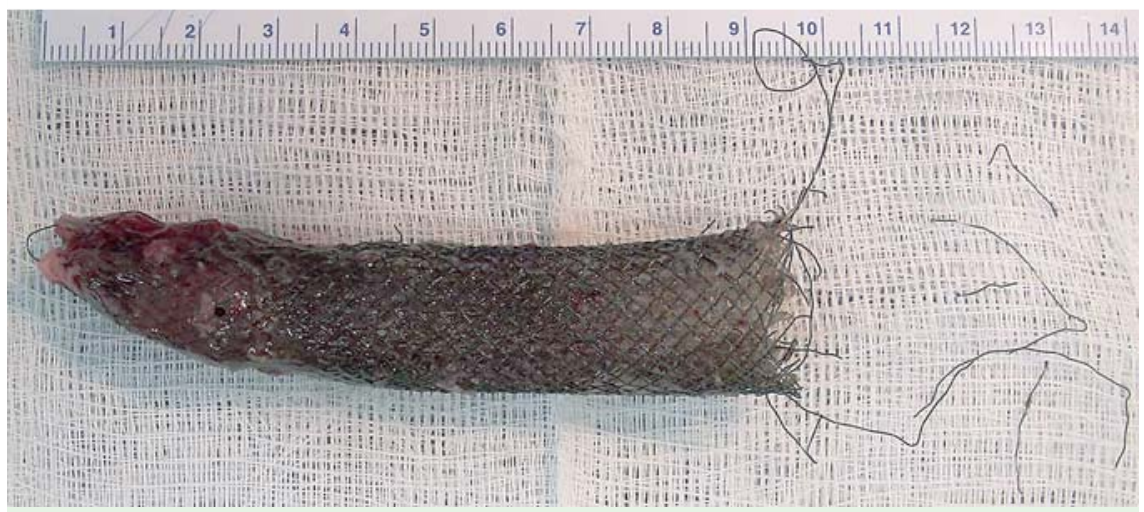

Fig. 2 Most of the stent was removed intact.

\section{Video 1}

The esophageal stent was broken at the proximal end but embedded into the mucosa and could not be removed. Three rat tooth forceps were used to collapse the proximal end of the stent. Argon plasma coagulation was used to cut portions of the stent, freeing the proximal flange of the stent. A distending diverticuloscope was placed by otolaryngologists and large alligator forceps were used to remove the stent from the mucosa. The stent was successfully removed without signs of perforation.

sis remained patent ( $\bullet$ Fig. 3 ). We recommend caution before deploying a partially covered metal stent in the esophagus for the treatment of benign strictures because its successful removal has a narrow window of safety.

Endoscopy_UCTN_Code_TTT_1AO_2AZ

Competing interests: None 
S. Mou' ${ }^{1}$, T. Kaltenbach ${ }^{1}$, M. Yao ${ }^{2}$, C. E. Corrales ${ }^{2}$, S. McGill ${ }^{1}$, R. Soetikno ${ }^{1}$

${ }^{1}$ Department of Medicine, Division of Gastroenterology, Stanford University School of Medicine, Veterans Affairs Palo Alto, Palo Alto, California, USA

2 Department of Otolaryngology, Stanford University School of Medicine, Veterans Affairs Palo Alto, Palo Alto, California, USA

\section{References}

1 Bakken JC, Wong Kee Song LM, de Groen PC et al. Use of a fully covered self-expandable metal stent for the treatment of benign esophageal diseases. Gastrointest Endosc 2010; 72 (Suppl. 04): $712-720$

2 Buscaglia JM, Ho S, Sethi A et al. Fully covered self-expandable metal stents for benign esophageal disease: A multicenter retrospective case series of 31 patients. Gastrointest Endosc 2011; 74 (Suppl. 01): 207-211

3 Buscaglia JM, Jayaraman V, Nagula S. Temporary use of a new fully-covered self-expanding metal stent for the management of post-esophagectomy strictures. Dig Endosc 2011; 23 (Suppl. 02): 187-189

4 Hirdes MM, Siersema PD, Houben MH et al. Stent-in-stent technique for removal of embedded esophageal self-expanding metal stents. Am J Gastroenterol 2011; 106 (Suppl. 02): $286-293$

5 Hirdes MM, Vleggaar FP, Van der Linde K et al. Esophageal perforation due to removal of partially covered self-expanding metal stents placed for a benign perforation or leak. Endoscopy 2011; 43 (Suppl. 02): 156 159

\section{Bibliography}

Dol http://dx.doi.org/

10.1055/s-0032-1308921

Endoscopy 2012; 44: E378-E379

(c) Georg Thieme Verlag KG

Stuttgart · New York

ISSN 0013-726X

\section{Corresponding author}

\section{R. Soetikno (Chief of Endoscopy)}

Veterans Affairs Palo Alto Health Care System 3801 Miranda Ave, Gl111

Palo Alto, CA 94304

USA

Fax: +650-849-0255

roy.soetikno@va.gov 